\title{
T Cell Cytokine Responses in Persons with Tuberculosis and Human Immunodeficiency Virus Infection
}

\author{
Ming Zhang, * Jianhua Gong, * Dinakar V. lyer, * Brenda E. Jones, * Robert L. Modlin, ` and Peter F. Barnes * \\ ${ }^{*}$ Department of Medicine, University of Southern California School of Medicine, Los Angeles, California 90033; and ${ }^{\ddagger}$ Division of \\ Dermatology and Department of Microbiology and Immunology, UCLA School of Medicine, Los Angeles, California 90024
}

\begin{abstract}
Tuberculosis causes more extensive and life-threatening disease in patients with HIV infection than in immunocompetent persons. To investigate the hypothesis that these severe manifestations of tuberculosis may be due to alterations in cytokine production, we evaluated cytokine patterns in HIV. infected tuberculosis patients. Upon stimulation with Mycobacterium tuberculosis in vitro, PBMC from HIV-infected tuberculosis patients had reduced proliferative and type 1 responses, compared with HIV-seronegative tuberculosis patients. The reduction in proliferative responses was independent of the CD4 cell count, but the reduced type 1 response was a direct result of CD4 cell depletion. There was no enhancement of type 2 cytokine production in HIV-infected patients, although production of IL-10 was prominent in all tuberculosis patients. In HIV-infected tuberculosis patients, $M$. tuberculosis-induced proliferative responses were significantly enhanced by neutralizing antibodies to IL-10 but not by antibodies to IL-4 or by recombinant IL-12. The $M$. tuberculosis-induced type 1 response was augmented both by antibodies to IL-10 and by recombinant IL-12. Tuberculosis in the context of HIV infection is characterized by diminished type 1 responses, probably induced by immunosuppressive cytokines produced by macrophages/monocytes, rather than by type 2 cells. (J. Clin. Invest. 1994. 94:2435-2442.) Key words: cytokine - T cell • Th1 • Th2 • tuberculosis • human immunodeficiency virus
\end{abstract}

\section{Introduction}

Tuberculosis caused an estimated 3.3 million deaths in 1992, prompting the World Health Organization to declare a global public health emergency. The manifestations of tuberculosis in HIV-infected patients are much more severe than in immunocompetent persons, characterized by frequent extrapulmonary and miliary disease, mycobacteremia, and high mortality rates $(1,2)$. This highly susceptible population has fueled deadly outbreaks of multidrug-resistant tuberculosis that are poorly responsive to standard chemotherapy (3-5). Development of adjunctive therapy to modulate antimycobacterial host defenses hinges on an improved understanding of the alterations in the

Address correspondence to Peter F. Barnes, HMR 904, University of Southern California, Los Angeles, CA 90033. 1994.

$$
\text { Received for publication } 5 \text { April } 1994 \text { and in revised form } 15 \text { July }
$$

J. Clin. Invest.

(c) The American Society for Clinical Investigation, Inc.

$0021-9738 / 94 / 12 / 2435 / 08 \quad \$ 2.00$

Volume 94, December 1994, 2435-2442 immune response in patients coinfected with Mycobacterium tuberculosis and HIV.

Immunologic resistance and susceptibility to intracellular pathogens in animals are mediated by $\mathrm{CD} 4^{+} \mathrm{T}$ cells with specific patterns of cytokine secretion. Th1 cells that produce interferon- $\gamma$ confer resistance to Leishmania infection, whereas Th2 cells that produce IL-4 exacerbate disease severity $(6,7)$. In patients infected with Mycobacterium leprae, type 1 cells that produce IFN- $\gamma$ and IL-2 predominate in tuberculoid leprosy patients with a resistant immune response, whereas type 2 cells producing IL-4 and IL-10 are dominant in lepromatous leprosy patients with ineffective immunity (8). The clinical manifestations of tuberculosis are also thought to reflect the immune response to infection (9). Advanced pulmonary tuberculosis represents an ineffective immune response, characterized by extensive and life-threatening disease and a high frequency of negative tuberculin skin tests. In contrast, patients with tuberculous pleuritis mount a resistant immune response, with spontaneous resolution of disease without therapy and a high frequency of positive tuberculin skin tests $(10,11)$. The type 1 cytokines IFN- $\gamma$ and IL-2 predominate at the site of disease in patients with pleuritis (12), but the pattern of cytokine production in patients with advanced pulmonary tuberculosis is uncertain. We hypothesized that the severe manifestations of tuberculosis in HIV-infected persons are due to alterations in the balance of $\mathrm{T}$ cell cytokines, and therefore evaluated the cytokine profile in patients coinfected with HIV and M. tuberculosis.

\section{Methods}

Patient population. Blood was obtained from 49 patients with their first episode of culture-proven tuberculosis. Acid-fast stains of sputum were positive in all patients. 23 patients had antibodies to HIV confirmed by Western blot, and 26 patients had negative ELISA tests for HIV antibody. The mean CD4 cell count in the HIV-infected patients was $126 \pm 49 / \mu \mathrm{l}$, and that in patients without HIV infection was $545 \pm 218$ / $\mu$ l. All patients had received less than two weeks of antituberculosis therapy at the time that blood samples were obtained.

Immunologic classification of patients. Patients with HIV infection were classified by a modification of methods outlined by Clerici et al. (13). PBMC were isolated by differential centrifugation over FicollPaque (Pharmacia Fine Chemicals, Piscataway, NJ), and plated in 200 $\mu$ l flat-bottomed wells at $2 \times 10^{5}$ cells/well in RPMI (GIBCO, Grand Island, NY) containing penicillin/streptomycin (GIBCO) and 10\% heat-inactivated human serum. PBMC were cultured in triplicate in the presence of $(a)$ media alone; $(b)$ heat-killed $M$. tuberculosis Erdman $(10 \mu \mathrm{g} / \mathrm{ml}) ;(c)$ irradiated PBMC (5,000 rad) from two unrelated HIVseronegative donors $\left(2 \times 10^{5}\right.$ cells/well); and $(d)$ PHA (GIBCO) diluted 1:200. Cells were maintained at $37^{\circ} \mathrm{C}$ and $7.5 \% \mathrm{CO}_{2}$. For stimulation with $M$. tuberculosis or allogeneic cells, proliferative responses were determined by measurement of $\left[{ }^{3} \mathrm{H}\right]$ thymidine incorporation after $6 \mathrm{~d}$ of culture, as described (14). For stimulation with PHA, $\left[{ }^{3} \mathrm{H}\right]-$ thymidine incorporation was determined after $72 \mathrm{~h}$ of culture. Patients were scored + or - for responses as follows: $M$. tuberculosis/allogeneic 
cells/PHA. Responses were considered positive if the delta cpm was greater than 1,000 and the stimulation index was greater than 3 .

Isolation of RNA and cDNA synthesis. Cells stimulated with $M$. tuberculosis were harvested after $24 \mathrm{~h}$, lysed with $4 \mathrm{M}$ guanidinium isothiocyanate, and stored at $-20^{\circ} \mathrm{C}$ before preparation of RNA, which was isolated as described (15). In some cases, purified CD4 ${ }^{+}$or CD8 ${ }^{+}$ cells were isolated from $M$. tuberculosis-stimulated cells by incubation with magnetic beads conjugated to anti-CD4 or to anti-CD8 (Dynal International, Skoyen, Norway), and passage through a magnetic activated cell sorter (Miltenyi Biotec, Bergisch-Gladbach, Germany), as previously described (16). Positively selected cells were 95-99\% $\mathrm{CD} 4^{+}$or $\mathrm{CD}^{+}$by cytofluorometric analysis, and were lysed with guanidinium isothiocyanate. In other experiments, RNA was isolated from freshly isolated unstimulated PBMC.

Complementary DNA was synthesized from RNA by priming $\sim 1$ $\mu \mathrm{g}$ of total RNA at $42^{\circ} \mathrm{C}$ for $1 \mathrm{~h}$ in a final vol of $50 \mu \mathrm{l}$ containing $1 \mu \mathrm{g}$ of an oligo dT primer (Pharmacia), $200 \mathrm{nmol}$ each of dNTP (Pharmacia) and mouse mammary leukemia virus reverse transcriptase (Bethesda Research Laboratories, Gaithersburg, MD) at 200 U/ $\mu$ g RNA.

Normalization of sample CD3 cDNA content by competitive PCR. To accurately compare cytokine mRNA expression in different samples, it is critical to use equivalent amounts of substrate cDNA. Because we wished to evaluate cytokines produced predominantly by $\mathrm{T}$ cells, we normalized all samples for CD3 cDNA content by competitive PCR. One set of primers amplifies both the CD3 $\delta$ chain cDNA in samples and a second DNA construct (MIMIC) which generates a PCR product of a size different from that of the target DNA (Clontech Laboratory, Inc., Palo Alto, CA). Serial twofold dilutions of known amounts of MIMIC cDNA were added to $1 \mu \mathrm{l}$ of sample cDNA and amplified by PCR, using oligonucleotide primers specific for CD3 $\delta$ chain cDNA. The primer sequences and reaction conditions have been previously published (17). For quantifying PCR product, $0.5 \mu \mathrm{Ci}$ of $\left[{ }^{32} \mathrm{P}\right] \mathrm{dCTP}$ (Amersham Corp., Arlington Heights, IL) was added to each reaction. A DNA thermocycler 480 (Perkin-Elmer Cetus, Norwalk, CT) ran 26 cycles of denaturation at $94^{\circ} \mathrm{C}$ for $1 \mathrm{~min}$ and annealing/extension at $65^{\circ} \mathrm{C}$ for $2 \mathrm{~min}$. PCR product $(10 \mu \mathrm{l})$ was subjected to electrophoresis on $1.5 \%$ agarose gels and visualized by staining with ethidium bromide. The sample and MIMIC PCR product bands were cut from the gel and radioactivity incorporation determined by liquid scintillation spectroscopy (LS 6000; Beckman Instruments, Inc., Fullerton, CA). When the sample and the MIMIC PCR product are equal, the amount of substrate sample cDNA is equal to that of substrate MIMIC cDNA. Therefore, by plotting the ratio of radioactivity incorporation of sample to MIMIC PCR product against the known amount of MIMIC substrate cDNA, the amount of substrate CD3 cDNA in each sample was calculated.

Quantitation of cytokine cDNA by competitive PCR. For each sample, aliquots containing 0.6 attomoles of CD3 cDNA were used as substrate and amplified by PCR with primers specific for cDNA of IFN- $\gamma$, IL-2, IL-4, and IL-10. The $5^{\prime}$ and $3^{\prime}$ primers for IFN- $\gamma$ were AGTTATATCTTGGCTTTTCAGCTCTGC and CCTCACCGAATAATTAGTCAGCTTTTC, respectively. The $5^{\prime}$ and $3^{\prime}$ primers for IL-4 were CCTCTGTTCTTCCTGCTAGCATGTGCC and CCAACGTACTCTGGTTGGCTTCCTTCA, respectively. The primer sequences for IL-2 and IL-10 and the reaction conditions for amplification of cytokine cDNA have been previously published (17). Serial dilutions of MIMIC for the appropriate cytokine cDNA were added to each reaction, and substrate cytokine cDNA quantitated as outlined above for CD3 cDNA. Upon PCR amplification of serial twofold dilutions of sample cDNAs, a concomitant decrease in sample PCR product and increase in MIMIC PCR product was observed, indicating that our PCR conditions were not within the plateau phase of amplification. Specificity of PCR amplification was confirmed by transfer of PCR product to nylon membranes and hybridization with a radiolabeled oligonucleotide probe complementary to sequences internal to those recognized by the CD3-specific primers, as previously described (17). Positive controls containing cytokine cDNA (from PHA-stimulated PBMC) and negative controls containing no cDNA were used in each set of reactions.

Measurement of cytokine concentrations by ELISA. For cells cul- tured in the presence of media alone or $M$. tuberculosis, supernatants were harvested after $24,48,72$, and $96 \mathrm{~h}$ and stored at $-70^{\circ} \mathrm{C}$. Cytokine concentrations were measured by ELISA (IFN- $\gamma$ and IL-2, Genzyme Corp., Cambridge, MA; IL-4, Monoclonal Antibody Technology, Stockholm, Sweden; IL-10, Biosource International, Camarillo, CA). Cytokine concentrations are shown as the concentration in supernatants of M. tuberculosis-stimulated cells minus that in supernatants of cells cultured in media alone. In more than $95 \%$ of the cases, no cytokines were detected in supernatants of cells cultured in media alone. In the few remaining cases, low levels $(<100 \mathrm{pg} / \mathrm{ml})$ of IFN- $\gamma$ and IL-10 were measured. Concentrations of IFN- $\gamma$ were maximal after $96 \mathrm{~h}$ of culture and are reported for that time point. Concentrations of IL-2 were determined after $24 \mathrm{~h}$ of culture. IL- 4 was not detected in supernatants at $24,48,72$, or $96 \mathrm{~h}$. Concentrations of IL-10 were maximal at $24 \mathrm{~h}$ and are reported for that time point.

Modulation of proliferative responses and interferon- $\gamma$ production by anticytokine antibodies and by $I L-12$. PBMC from HIV-infected tuberculosis patients were cocultured with $M$. tuberculosis and proliferative responses determined as outlined above. In some cases, neutralizing antibodies to human IL-4 (Genzyme Corp.) and to human IL-10 (Biosource International) were added at $10 \mu \mathrm{g} / \mathrm{ml}$ to some wells. In other cases, recombinant human IL-12 (kind gift of Dr. Maurice Gately, Hofmann La Roche, Inc., Nutley, NJ) was added at $10 \mathrm{ng} / \mathrm{ml}$. Supernatants for determination of IFN- $\gamma$ concentrations were harvested in some cases, as outlined above. As controls for the addition of anti-IL-4 or antiIL-10, isotype control antibodies were also added to M. tuberculosisstimulated cells.

Statistical analysis. Continuous variables that were normally distributed were compared by the Student's $t$ test. Variables that were not normally distributed were compared by the nonparametric Wilcoxon rank-sum test.

\section{Results}

Proliferative responses by $\mathrm{M}$. tuberculosis-stimulated PBMC. PBMC from $16 \mathrm{HIV}$-infected tuberculosis patients and from 14 tuberculosis patients without HIV infection were stimulated in vitro with heat-killed $M$. tuberculosis. The proliferative response was significantly reduced in HIV-infected patients, compared to those without HIV infection (mean delta cpm $15,110 \pm 5,452$, vs $62,593 \pm 15,626, P<0.01$ ). In 10 healthy tuberculin reactors with a protective immune response to $M$. tuberculosis, the mean delta cpm was $117,179 \pm 14,017$. In HIVinfected patients, the mean delta cpm in eight patients with more than $100 \mathrm{CD} 4$ cells / $\mu$ l was $11,253 \pm 3,534$, compared with $18,967 \pm 5,219$ in eight patients with fewer than 100 CD4 cells/ $\mu \mathrm{l}$. There was no correlation between the delta cpm and the CD4 cell count $(r=0.23)$, indicating that the reduced proliferative response was not simply due to a lack of CD4 cells.

Cytokine production by M. tuberculosis-stimulated PBMC. Concentrations of interferon- $\gamma$ in cell culture supernatants were reduced in HIV-infected tuberculosis patients, compared with tuberculosis patients without HIV infection $(822 \pm 336 \mathrm{pg} / \mathrm{ml}$, vs $2,278 \pm 582 \mathrm{pg} / \mathrm{ml}, P=0.004$, Fig. 1 ). IL-2 was barely detectable $(90 \pm 36 \mathrm{pg} / \mathrm{ml}$ for HIV-infected patients, vs $86 \pm 26$ $\mathrm{pg} / \mathrm{ml}$ for patients without HIV infection). IL-4 was not detected in any of the supernatants. IL-10 concentrations were comparable in patients with and without HIV infection $(711 \pm 187 \mathrm{pg} / \mathrm{ml}$ vs $578 \pm 85 \mathrm{pg} / \mathrm{ml})$. Thus, production of the type 1 cytokine IFN- $\gamma$ was reduced in HIV-infected patients, whereas production of the type 2 cytokine IL- 10 was comparable to that in patients without HIV infection.

Cytokine mRNA expression in M. tuberculosis-stimulated $P B M C$. IL-2 and IL-4 are difficult to detect in cell culture super- 


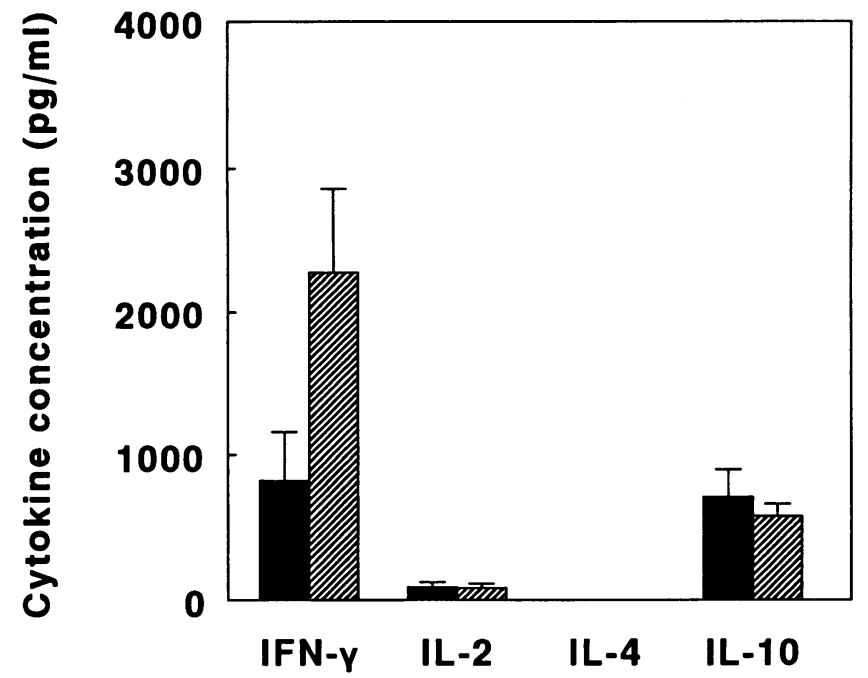

Figure 1. Production of cytokines by PBMC from tuberculosis patients with or without HIV infection. PBMC were isolated from tuberculosis patients with ( $\square$ ) or without ( $\square$ ) HIV infection, and cocultured with $M$. tuberculosis. Cytokine concentrations were determined in cell culture supernatants by ELISA.

natants because they may be used by cells during the course of culture. To more fully characterize the pattern of cytokine production in HIV-infected tuberculosis patients, we used quantitative reverse transcription (RT) ${ }^{1}$-PCR with internal controls to evaluate mRNA expression for IFN- $\gamma$, IL-2, IL-4, and IL10 in $M$. tuberculosis-stimulated PBMC from 12 HIV-infected tuberculosis patients and 13 tuberculosis patients without HIV infection. For each sample, 0.6 attomoles of CD3 cDNA was amplified by PCR with cytokine-specific primers. mRNA expression for the type 1 cytokines IFN- $\gamma$ and IL- 2 was significantly reduced in HIV-infected patients $(P<0.01$ for IFN- $\gamma$ and IL-2), whereas mRNA expression for the type 2 cytokines IL-4 and IL-10 was comparable in both groups (Fig. 2). These results provide additional evidence that coinfection with HIV in tuberculosis patients results in a diminished type 1 response without enhanced production of type 2 cytokines.

Clerici and colleagues have classified asymptomatic HIVinfected patients on the basis of proliferative responses to nominal antigen, alloantigen, and mitogen. In patients with reduced proliferative responses to nominal antigen but not to alloantigen and mitogen $(-l+l+)$, production of the type 2 cytokine IL4 is enhanced, and IL-4 in turn downregulates proliferative responses to nominal antigen (18). In our patients, mean IL-4 mRNA expression in $8-/+/+$ patients was $2.9 \times 10^{-4} \mathrm{aM}$ (range 1.0-4.7 $\times 10^{-4} \mathrm{aM}$ ), compared with $12.9 \times 10^{-4} \mathrm{aM}$ (range 0.9 to $23.2 \times 10^{-4} \mathrm{aM}$ ) in $5+/+/+$ patients. Mean IL10 mRNA expression in $-/+/+$ and $+/+/+$ patients was also similar (data not shown). These results indicate that, in the context of tuberculosis, mRNA expression for type 2 cytokines is not increased in HIV-infected persons classified as $-I+l+$.

Cytokine mRNA expression in unstimulated PBMC. To determine if the changes in $M$. tuberculosis-stimulated cells reflected changes in vivo, we evaluated cytokine mRNA expression in unstimulated PBMC from $11 \mathrm{HIV}$-infected tuberculosis

1. Abbreviation used in this paper: RT, reverse transcription.
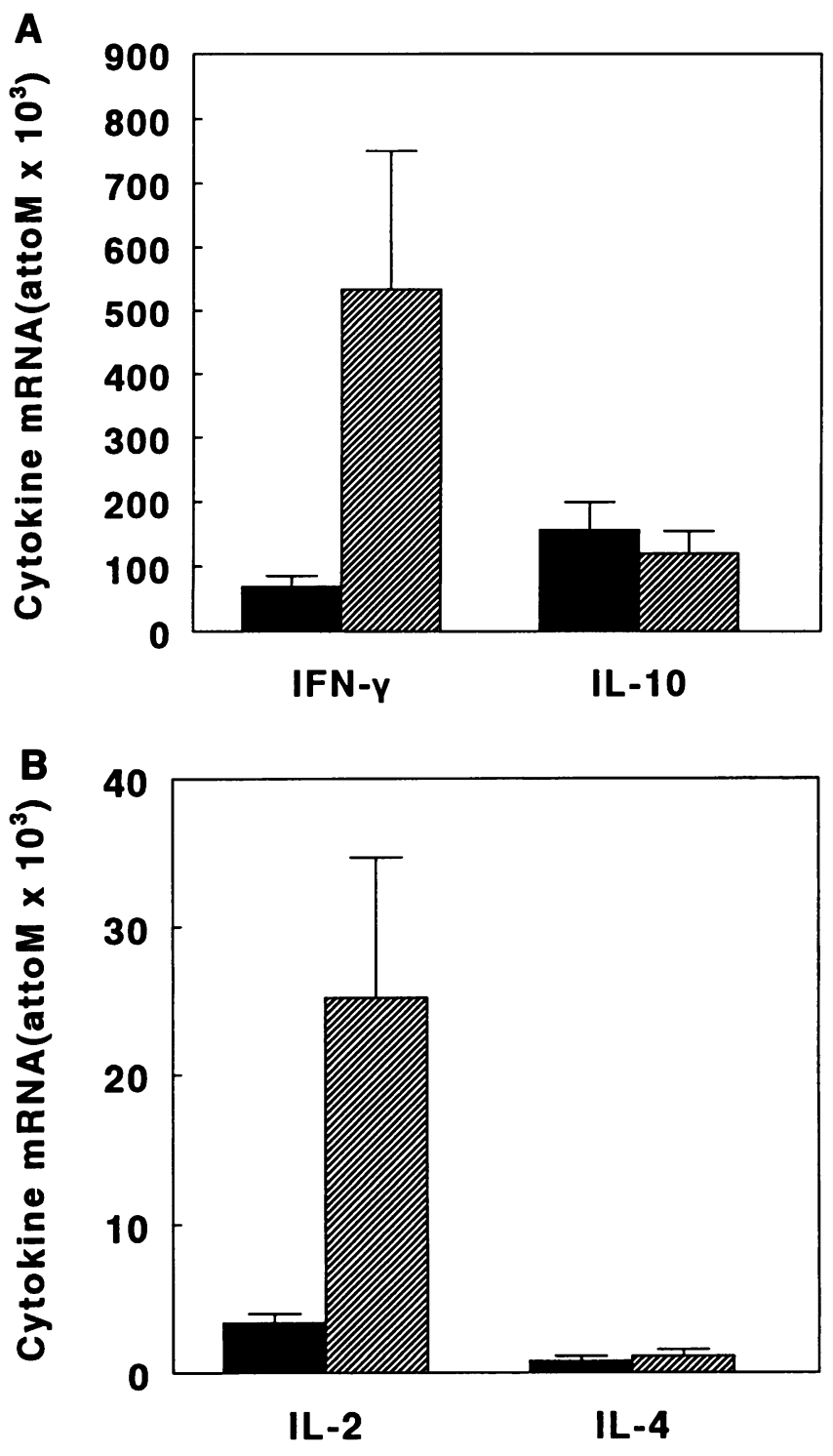

Figure 2. Expression of cytokine mRNA by PBMC from tuberculosis patients with or without HIV infection. PBMC were isolated from tuberculosis patients with ( $\square$ ) or without ( $\square$ ) HIV infection, and cocultured with $M$. tuberculosis. Cytokine mRNA expression was determined by quantitative RT-PCR, amplifying aliquots containing $0.6 \mathrm{M}$ of $\mathrm{CD} 3$ cDNA. Expression of mRNA for IFN- $\gamma$ and IL-10 is shown in $A$, and expression of mRNA for IL-2 and IL- 4 is shown in $B$.

patients and 11 tuberculosis patients without HIV infection. mRNA for IL-2, IL-4, and IL-10 were absent or barely detectable in most patients (data not shown). mRNA expression for IFN- $\gamma$ was comparable in tuberculosis patients with or without HIV infection (mean $6.1 \pm 2.2 \times 10^{-3} \mathrm{aM}$ vs $4.4 \pm 3.1 \times 10^{-3} \mathrm{aM}$, respectively, $P>0.05)$.

Cytokine mRNA expression in CD4 cells. The reduced production of type 1 cytokines in HIV-infected tuberculosis patients may have resulted from the reduced number of CD4 cells in PBMC of HIV-infected tuberculosis patients, or from diminished cytokine production per CD4 cell. To distinguish these possibilities, we obtained $M$. tuberculosis-stimulated PBMC from nine HIV-infected tuberculosis patients and seven tuberculosis patients without HIV infection. Immunomagnetic 

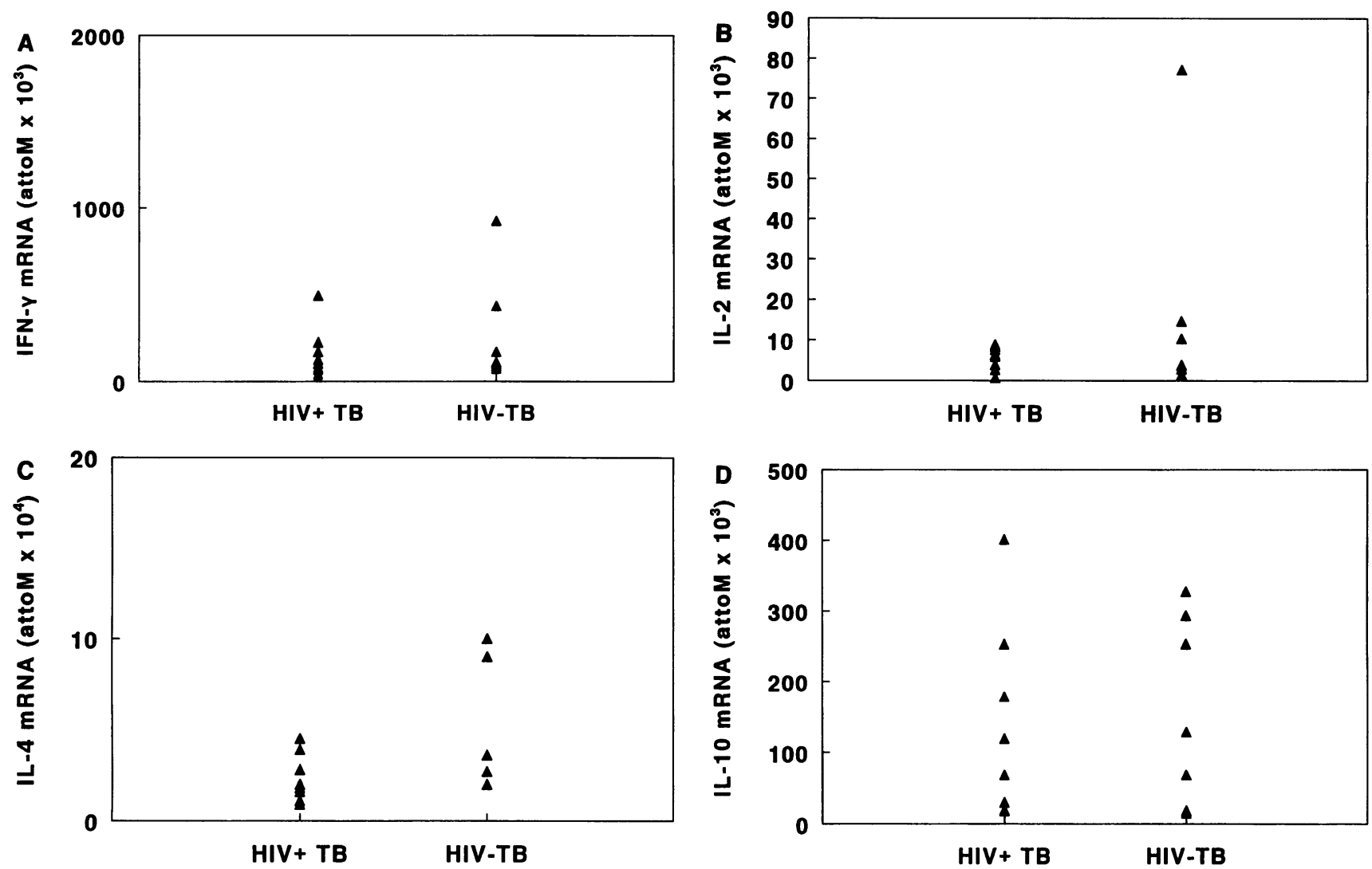

Figure 3. Expression of mRNA for interferon- $\gamma$ (A), IL-2 (B), IL-4 (C), and IL-10 (D) by CD4 cells from tuberculosis patients with or without HIV infection. PBMC from patients with (HIV+ TB) or without HIV infection (HIV - TB) were cocultured with M. tuberculosis, and CD4 cells isolated by immunomagnetic selection. Cytokine mRNA expression was determined in CD4 cells by quantitative RT-PCR.

selection was used to isolate populations that were $95-99 \%$ CD4 cells. Quantitative RT-PCR analysis of these CD4 cells demonstrated that, unlike the case for PBMC, expression of mRNA for IFN- $\gamma$, IL-2, IL-4, and IL-10 were similar in tuberculosis patients with or without HIV infection (Fig. 3 ). The cytokine profiles of sorted CD8 cells were also identical for the two groups (data not shown). These results indicate that coinfection with HIV did not alter type 1 or type 2 cytokine production per CD4 cell, and that the reduction in type 1 cytokine mRNA expression in HIV-infected tuberculosis patients reflected the depressed CD4 cell counts in these individuals.

Modulation of proliferative responses in HIV-infected tuberculosis patients. We hypothesized that the reduced proliferative responses in HIV-infected tuberculosis patients may be mediated by the type 2 cytokines IL- 4 and/or IL-10, which can inhibit antigen-induced proliferation by deactivation of antigenpresenting cells and downregulation of macrophage MHC class II expression (19-24). To evaluate this hypothesis, PBMC from HIV-infected tuberculosis patients were cocultured with $M$. tuberculosis, or with $M$. tuberculosis and neutralizing antibodies to IL-4 or to IL-10. In HIV-infected patients classified as $-I+/+$, anti-IL-4 and IL-10 enhanced the proliferative response to influenza virus $(18,25)$. We therefore analyzed our results separately for HIV-infected tuberculosis patients classified as $-1+1+$ and $+/+/+$. In both groups, anti-IL-4 had minimal effects on $M$. tuberculosis-induced proliferation (Fig. $4)$. In contrast, anti-IL-10 enhanced proliferation in all 5 patients classified as $-I+/+$ and in 11 of 12 patients classified as $+/+/+$ (Fig. 5, $A$ and $B$ ). In the 17 patients, mean delta cpm in response to $M$. tuberculosis increased from 18,456 $\pm 5,211$ to $40,883 \pm 11,320$ with addition of anti-IL-10 $(P=0.006)$. Control experiments using isotype control antibodies for anti-IL10 did not affect $M$. tuberculosis-induced proliferation. Addition of anti-IL-4 or anti-IL-10 alone in the absence of $M$. tuberculosis did not result in cell proliferation. In 11 tuberculosis patients without HIV infection, addition of anti-IL-10 augmented the proliferative response to $M$. tuberculosis in a few patients, but the change was not statistically significant for the group as a whole (Fig. $5 C$, mean delta cpm 44,120 $\pm 15,829$, vs $56,316 \pm 19,079, P>0.05)$. These results suggest that the low proliferative responses to $M$. tuberculosis in HIV-infected tuberculosis patients are mediated through IL-10.

IL-12 favors development of Th1 cells in vitro $(26,27)$ and in vivo $(28,29)$, and can restore $\mathrm{T}$ cell proliferative responses to HIV envelope peptides (30). We therefore evaluated the effects of recombinant IL-12 on the M. tuberculosis-induced proliferative response of PBMC from HIV-infected tuberculosis patients. IL- 12 enhanced the proliferative response in 2 of 5 patients classified as $-/+/+$, and in 7 of 12 patients classified as $+/+/+$ (Fig. 6). However, the increase in mean delta cpm in response to $M$. tuberculosis with addition of IL-12 was not statistically significant $(16,421 \pm 4,801$ vs $24,060 \pm 7,086, P>0.05)$. Addition of both anti-IL-10 and IL-12 did not yield additive augmentation of the proliferative response, which were comparable with those obtained with addition of anti-IL-10 alone in seven out of eight patients (data not shown). In 10 tuberculosis patients with- 

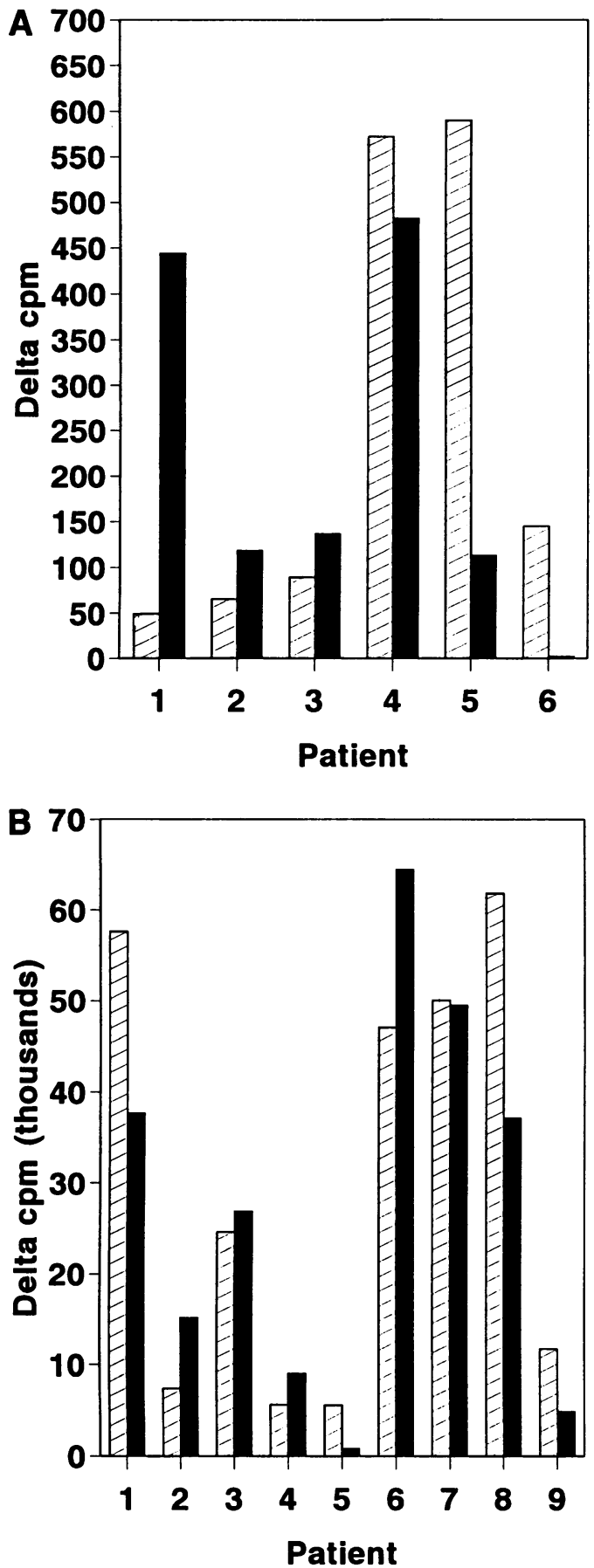

Figure 4. Effect of neutralizing antibodies to IL-4 on the $M$. tuberculosis-induced proliferative response of PBMC from HIV-infected tuberculosis patients. Proliferative responses to $M$. tuberculosis were determined in the absence and presence of neutralizing antibodies to IL-4 for patients classified as $-I+I+(A)$ and $+I+I+(B)$. $\mathbf{n}$, TB; $\mathbf{\square}$, TB + anti-IL-4.

out HIV infection, the proliferative response to $M$. tuberculosis did not change significantly with addition of IL-12 (mean delta cpm $55,599 \pm 14,992$ vs 70,057 $\pm 14,033, P>0.05)$.

Effects of anti-IL-10 and IL-12 on the type 1 response. Because anti-IL-10 and IL-12 enhanced the M. tuberculosisinduced proliferative response in some patients, we wished to evaluate the effect of these agents on the type 1 response. Con- centrations of IFN- $\gamma$ in supernatants of $M$. tuberculosis-stimulated cells were significantly higher after addition of anti-IL10 or recombinant IL-12 (Fig. 7), indicating that the type 1 response was enhanced. Because antibodies to IL-10 and recombinant IL-12 can induce natural killer cells to produce IFN- $\gamma$ (31-33), we stimulated PBMC with anti-IL-10 or IL-12 alone, in the absence of $M$. tuberculosis. Under these conditions, the maximum concentration of IFN- $\gamma$ in supernatants was $200 \mathrm{pg} /$ $\mathrm{ml}$, which was insufficient to account for the marked increases in IFN- $\gamma$ production observed upon addition of anti-IL-10 or IL-12 to M. tuberculosis-stimulated PBMC.

\section{Discussion}

Persons with HIV infection are at markedly increased risk for development of disease from recent and remote infection with $M$. tuberculosis (34-36). In addition, the manifestations of tuberculosis in HIV-infected persons are often severe and lifethreatening $(1,2)$. The data presented in this report indicate that, in the context of coinfection with HIV and M. tuberculosis, the proliferative and type 1 responses to $M$. tuberculosis are reduced without enhancement of the type 2 response. Reduction in the proliferative response was independent of the CD4 cell count, but the diminished type 1 cytokine response was a direct result of the reduced CD4 cell count in HIV-infected patients. The depressed proliferative and type 1 responses are reversed by neutralizing antibodies to IL-10, but not by antibodies to IL4. These results suggest that the reduced proliferative and type 1 responses in HIV-infected tuberculosis patients are mediated by immunosuppressive cytokines produced by macrophages/ monocytes, rather than by type 2 cells.

Recent evidence suggests that IL-10 plays a central role in enhancing intracellular survival of mycobacteria, as antibodies to IL-10 inhibit mycobacterial growth in human monocytes (37, 38). Although the mechanism underlying this effect is uncertain, it is noteworthy that the putative mycobacterial virulence factor lipoarabinomannan, a heteropolysaccharide attached to the mycobacterial cell membrane, induces production of IL-10 (15), which in turn inhibits antigen-specific $T$ cell proliferation and type 1 cytokine production in patients with leprosy (16). Our results suggest that the reduced proliferative and type 1 responses in HIV-infected tuberculosis patients are mediated at least in part through IL-10. Anti-IL-10 markedly enhanced the $M$. tuberculosis-induced proliferative response in HIV-infected tuberculosis patients, whereas the effect was variable in tuberculosis patients without HIV infection, despite production of comparable levels of IL-10 by PBMC from both groups. Macrophages and/or T cells from HIV-infected patients may express higher levels of IL-10 receptors and therefore be more sensitive to the effects of IL-10 than are patients without HIV infection. Additional studies are needed to clarify this issue.

IL-4, a potent cross-regulatory cytokine produced by Th2 cells, inhibits development of Th1 cells in vitro and in vivo. $\mathrm{T}$ cells cocultured with $M$. tuberculosis and IL-2 secrete a Th1 cytokine pattern, but addition of IL- 4 favors development of Th2 cells (39). Similarly, in mice primed with a helminth infection to boost IL-4 production, subsequent challenge with $M$. tuberculosis results in a Th2 response (40). Our data indicate that, in HIV-infected tuberculosis patients, the reduced proliferative and type 1 responses are not mediated by IL-4, and therefore not by type 2 cells. In contrast, Clerici et al. (18) demonstrated that, in HIV-infected patients classified as $-/+1+, \mathrm{T}$ 

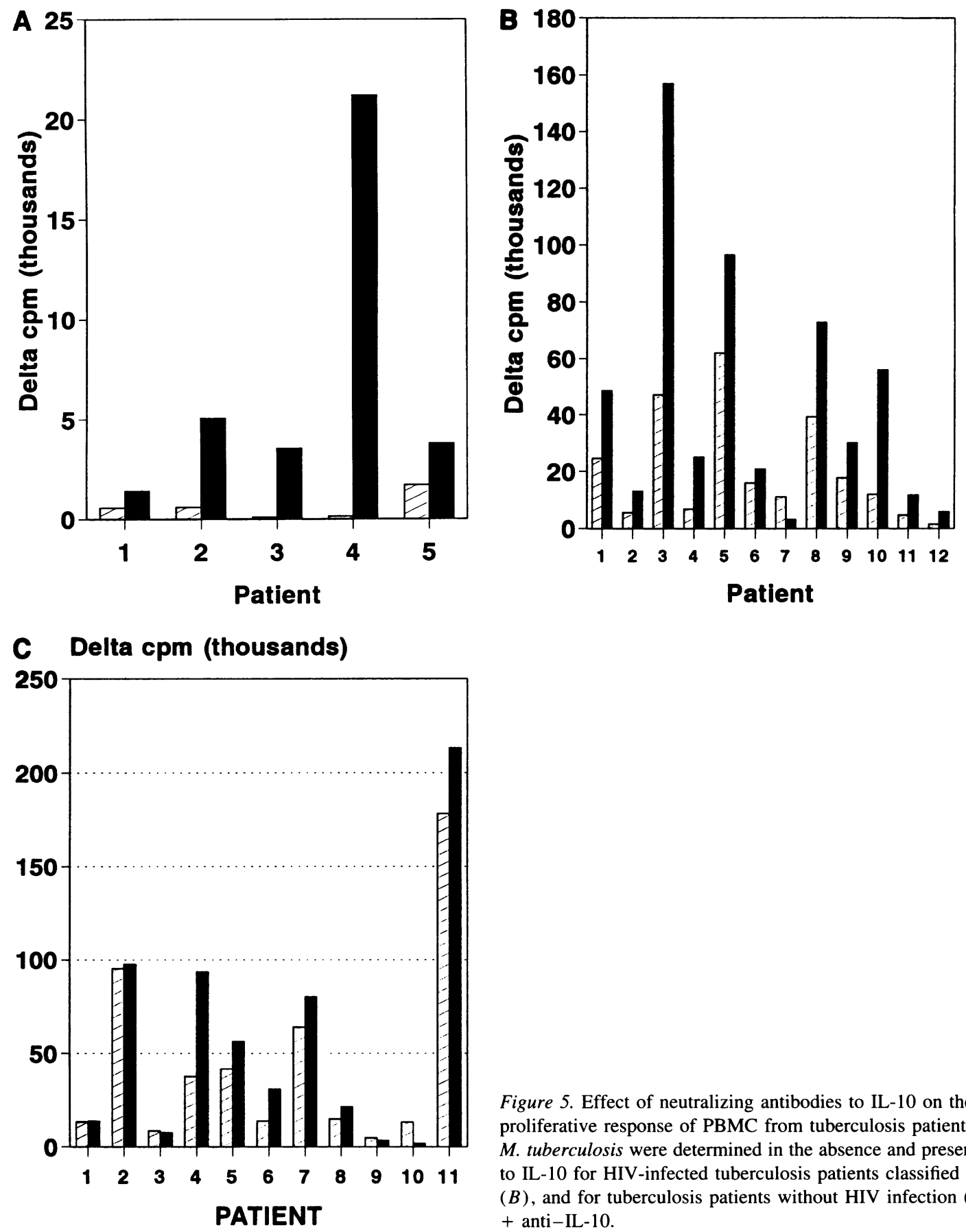

Figure 5. Effect of neutralizing antibodies to IL-10 on the M. tuberculosis-induced proliferative response of PBMC from tuberculosis patients. Proliferative responses to $M$. tuberculosis were determined in the absence and presence of neutralizing antibodies to IL-10 for HIV-infected tuberculosis patients classified as $-I+/+(A)$ and $+/+I+$ $(B)$, and for tuberculosis patients without HIV infection $(C)$. $\mathbf{m}, \mathrm{TB} ; \mathbf{a}, \mathrm{TB}$ + anti-IL-10.

cell production of IL-4 is enhanced, and reduced proliferation and IL-2 production in response to influenza and tetanus are restored by neutralizing antibodies to IL-4. These disparities probably reflect differences in our patient populations and experimental systems. Clerici's patients were asymptomatic and were at an early stage of HIV infection before development of opportunistic infections, whereas our patients were at an advanced stage of HIV infection and were coinfected with $M$. tuberculosis. Clerici's patients had CD4 cell counts of 400 $800 / \mu \mathrm{l}$, but our patients had a mean CD4 cell count of $\sim 100 /$ $\mu \mathrm{l}$. In addition, Clerici evaluated proliferative and cytokine responses to influenza and tetanus, whereas we evaluated the responses to $M$. tuberculosis. At an early stage of HIV-induced immunodeficiency, type 2 cells may be prominent, but as HIV disease progresses, immunosuppression may be mediated predominantly by macrophages that produce IL-10 and perhaps other immunosuppressive cytokines such as transforming growth factor- $\beta$ (41).

IL-12 has a wide range of immunostimulatory properties, including enhancement of cytotoxic $\mathrm{T}$ cell activity, $\mathrm{T}$ cell proliferation, natural killer cell activity, and IFN- $\gamma$ production (4245 ). During initial infection with an intracellular pathogen, IL12 is thought to induce natural killer cells to release IFN- $\gamma$, with subsequent augmentation of the Th1 response. In asymptomatic HIV-infected patients, IL-12 enhances the T cell proliferative responses to influenza peptide and to HIV envelope protein 

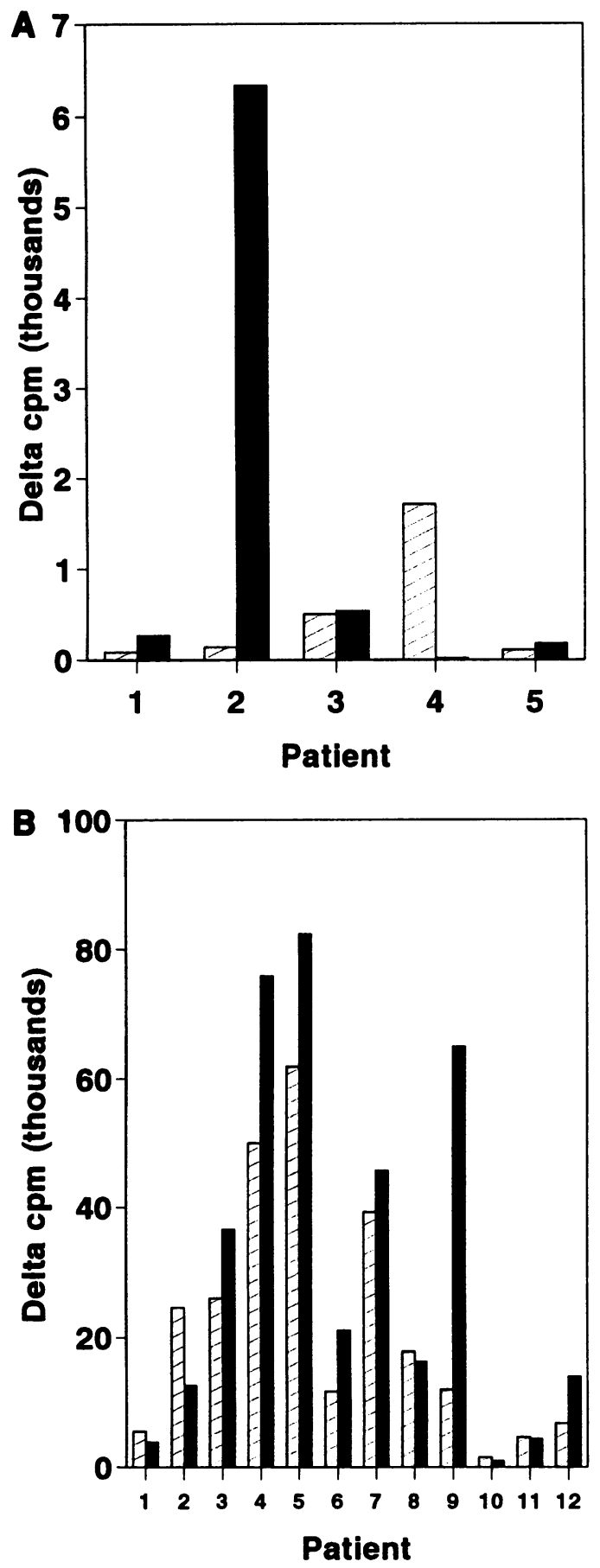

Figure 6. Effect of recombinant IL-12 on the M. tuberculosis-induced proliferative response of PBMC from HIV-infected tuberculosis patients. Proliferative responses to $M$. tuberculosis were determined in the absence and presence of recombinant IL- 12 for patients classified as $-I+I+(A)$ and $+I+I+(B) . \mathbf{m}$ TB; $\mathbf{m}, \mathrm{TB}+\mathrm{IL}-12$.

(30). In HIV-infected tuberculosis patients, we found that IL12 enhanced $M$. tuberculosis-induced production of IFN- $\gamma$, but did not significantly augment the proliferative response to $M$. tuberculosis. These results suggest that the reduced proliferative responses observed in most HIV-infected tuberculosis patients are not mediated by insufficient IL-12 production. Alternatively, the derangements in the immune response in these severely ill

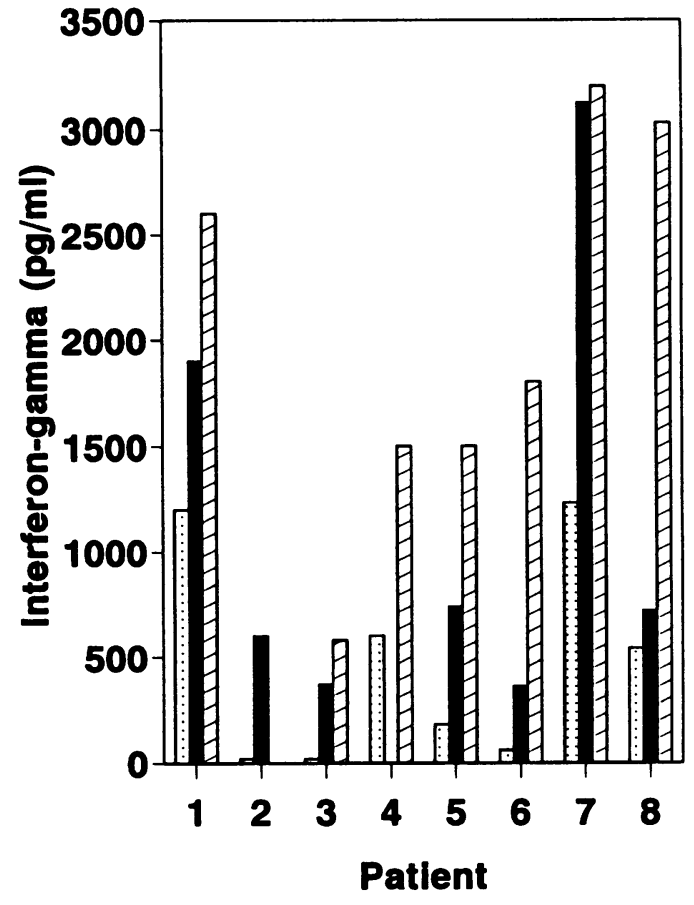

Figure 7. Effects of anti-IL-10 and recombinant IL-12 on M. tuberculosis-induced production of IFN- $\gamma$ by PBMC from HIV-infected tuberculosis patients. PBMC were cocultured with $M$. tuberculosis and concentrations of IFN- $\gamma$ determined in cell culture supernatants, in the absence and presence of antibodies to IL-10 or recombinant IL-12. Antibodies to IL-10 were not added to PBMC from patient 4 , and recombinant IL12 was not added to PBMC from patient 2 ., TB; $₫$, TB + anti-IL10; $\mathbf{\square}$, TB + IL-12.

patients may be so marked that addition of IL-12 alone does not restore proliferative responses. Additional studies are needed to clarify the possible interactions between IL-10 and IL-12 and their role in antimicrobial defenses in HIV-infected individuals. Such studies may lead to development of immunologic interventions to improve outcome in HIV-infected persons with opportunistic infection.

\section{Acknowledgments}

We thank Dr. Maurice Gately for provision of recombinant IL-12, Drs. Patrick Brennan and John Belisle for provision of $M$. tuberculosis Erdman, Dr. Yuanguang Lin for expert technical assistance, and Claire Hughlett and Michiko Otaya for assistance in obtaining patient blood samples.

This work was supported by the United Nations Development Program (UNDP)/World Bank/World Health Organization Special Programme for Vaccine Development (IMMMYC), the Heiser Program for Research in Leprosy and Tuberculosis, the National Institutes of Health (AI27285, AI36069), the Centers for Disease Control (cooperative agreement CCU 901877), and the American Lung Association of Los Angeles County. Computational assistance and molecular core laboratory facilities were provided by the National Institutes of Health National Center for Research Resources of the General Clinical Research Centers grant M01 RR-43. Mycobacterial products were provided through contract AI05074 from the National Institute of Allergy and Infectious Diseases.

\section{References}

1. Barnes, P. F., A. B. Bloch, P. T. Davidson, and D. E. Snider, Jr. 1991. Tuberculosis in patients with human immunodeficiency virus infection. $N$. Engl. J. Med. 324:1644-1650. 
2. Hopewell, P. C. 1992. Impact of human immunodeficiency virus infection on the epidemiology, clinical features, management, and control of tuberculosis. Clin. Infect. Dis. 15:540-547.

3. Centers for Disease Control, 1991. Nosocomial transmission of multidrugresistant tuberculosis among HIV-infected persons, Florida and New York, 19881991. Morb. Mortal. Wkly. Rep. 40:585-591.

4. Fischl, M. A., G. L. Daikos, R. B. Uttamchandani, R. B. Poblete, J. N. Moreno, R. R. Reyes, A. M. Boota, L. M. Thompson, T. J. Cleary, S. A. Oldham, et al. 1992. Clinical presentation and outcome of patients with HIV infection and tuberculosis caused by multiple-drug-resistant bacilli. Ann. Intern. Med. 117:184-190.

5. Edlin, B. R., J. I. Tokars, M. H. Grieco, J. T. Crawford, J. Williams, E. M Sordillo, K. R. Ong, J. O. Kilburn, S. W. Dooley, K. G. Castro, et al. 1992. An outbreak of multidrug-resistant tuberculosis among hospitalized patients with the acquired immunodeficiency syndrome. N. Engl. J. Med. 326:1514-1521.

6. Scott, P. 1993. IL-12: Initiation cytokine for cell-mediated immunity. Science (Wash. DC). 260:496-497.

7. Heinzel, F. P., M. D. Sadick, B. J. Holaday, R. L. Coffman, and R. M. Locksley. 1989. Reciprocal expression of interferon gamma or interleukin 4 during the resolution or progression of murine leishmaniasis. Evidence for expansion of distinct helper T cell subsets. J. Exp. Med. 169:59-72.

8. Yamamura, M., K. Uyemura, R. J. Deans, K. Weinberg, T. H. Rea, B. R. Bloom, and R. L. Modlin. 1991. Defining protective responses to pathogens: cytokine profiles in leprosy lesions. Science (Wash. DC). 254:277-279.

9. Barnes, P. F., R. L. Modlin, and J. J. Ellner. 1994. T-cell responses and cytokines. In Tuberculosis: Pathogenesis, Protection and Control. B. R. Bloom, editor. American Society for Microbiology, Washington, DC. 417-435.

10. Roper, W. H., and J. J. Waring. 1955. Primary serofibrinous pleural effusion in military personnel. Am. Rev. Tuberc. Pulm. Dis. 71:616-634.

11. Antoniskis, D., K. Amin, and P. F. Barnes. 1990. Pleuritis as a manifestation of reactivation tuberculosis. Am. J. Med. 89:447-450.

12. Barnes, P. F., S. Lu, J. S. Abrams, E. Wang, M. Yamamura, and R. L. Modlin. 1993. Cytokine production at the site of disease in human tuberculosis. Infect. Immun. 61:3482-3489.

13. Clerici, M., N. I. Stocks, R. A. Zajac, R. N. Boswell, D. R. Lucey, C. S Via, and G. M. Shearer. 1989. Detection of three distinct patterns of T helper cell dysfunction in asymptomatic, human immunodeficiency virus-seropositive patients. Independence of CD4+ cell numbers and clinical staging. J. Clin. Invest. 84:1892-1899.

14. Barnes, P. F., V. Mehra, G. R. Hirschfield, S-J. Fong, C. Abou-Zeid, G. A. W. Rook, S. W. Hunter, P. J. Brennan, and R. L. Modlin. 1989. Characterization of T-cell antigens associated with the cell wall protein-peptidoglycan complex of Mycobacterium tuberculosis. J. Immunol. 143:2656-2662.

15. Barnes, P. F., D. Chatterjee, J. S. Abrams, S. Lu, E. Wang, M. Yamamura, P. J. Brennan, and R. L. Modlin. 1992. Cytokine production induced by Mycobacterium tuberculosis lipoarabinomannan. Relationship to chemical structure. J. Immunol. 149:541-547.

16. Sieling, P. A., J. S. Abrams, M. Yamamura, P. Salgame, B. R. Bloom, T. H. Rea, and R. L. Modlin. 1993. Immunosuppressive roles for interleukin-10 and interleukin-4 in human infection: in vitro modulation of $\mathrm{T}$ cell responses in leprosy. J. Immunol. 150:5501-5510.

17. Pirmez, C., M. Yamamura, K. Uyemura, M. Paes-Oliveira, F. ConceicaoSilva, and R. L. Modlin. 1993. Cytokine patterns in the pathogenesis of human leishmaniasis. J. Clin. Invest. 91:1390-1395.

18. Clerici, M., F. T. Hakim, D. J. Venzon, S. Blatt, C. W. Hendrix, T. A. Wynn, and G. M. Shearer. 1993. Changes in interleukin-2 and interleukin-4 production in asymptomatic, human immunodeficiency virus-seropositive individuals. J. Clin. Invest. 9184:759-765.

19. Lehn, M., W. Y. Weiser, S. Engelhorn, S. Gillis, and H. G. Remold. 1989. IL-4 inhibits $\mathrm{H}_{2} \mathrm{O}_{2}$ production and antileishmanial capacity of human cultured monocytes mediated by IFN- $\gamma$. J. Immunol. 143:3020-3024.

20. Ho, J. L., S. H. He, M. J. C. Rios, and E. A. Wick. 1992. Interleukin-4 inhibits human macrophage activation by tumor necrosis factor, granulocytemonocyte colony-stimulating factor, and interleukin-3 for antileishmanial activity and oxidative burst capacity. J. Infect. Dis. 165:344-351.

21. de Waal Malefyt, R., J. Haanen, H. Spits, M-G. Roncarlo, A. te Velde C. Figdor, K. Johnson, R. Kastelein, H. Yssel, and J. E. De Vries. 1991. Interleukin-10 (IL-10) and viral IL-10 strongly reduce antigen-specific human T cell proliferation by diminishing the antigen-presenting capacity of monocytes via downregulation of class II major histocompatibility complex expression. J. Exp. Med. 174:915-924.

22. de Waal Malefyt, R., J. Abrams, B. Bennett, C. Figdor, and J. E. De Vries. 1991. IL-10 inhibits cytokine synthesis by human monocytes: an autoregulatory role of IL-10 produced by monocytes. J. Exp. Med. 174:1209-1220.

23. Fiorentino, D. F., A. Zlotnik, P. Vieira, T. R. Mosmann, M. Howard, K. W. Moore, and A. O'Garra. 1991. IL-10 acts on the antigen-presenting cell to inhibit cytokine production by Th1 cells. J. Immunol. 146:3444-3451.

24. Bogdan, C., Y. Vodovotz, and C. Nathan. 1991. Macrophage deactivation by interleukin 10. J. Exp. Med. 174:1549-1555.

25. Clerici, M., T. A. Wynn, J. A. Berzofsky, S. P. Blatt, C. W. Hendrix, A.
Sher, R. L. Coffman, and G. M. Shearer. 1994. Role of interleukin-10 in T helper cell dysfunction in asymptomatic individuals infected with the human immunodeficiency virus. J. Clin. Invest. 93:768-775.

26. Manetti, R., P. Parronchi, M. G. Giudizi, M. P. Piccinni, E. Maggi, G. Trinchieri, and S. Romagnani. 1993. Natural killer cell stimulatory factor (interleukin 12 [IL-12]) induces T helper type 1 ( Thl)-specific immune responses and inhibits the development of IL-4-producing Th cells. J. Exp. Med. 177:11991204.

27. Hsieh, C.-S., S. E. Macatonia, C. S. Tripp, S. F. Wolf, A. O'Garra, and K. M. Murphy. 1993. Development of $\mathrm{T}_{\mathrm{H}} 1 \mathrm{CD} 4+\mathrm{T}$ cells through IL-12 produced by Listeria-induced macrophages. Science (Wash. DC). 260:547-549.

28. Sypek, J. P., C. L. Chung, S. E. H. Mayor, J. M. Subramanyam, S. J. Goldman, D. S. Sieburth, S. F. Wolf, and R. G. Schaub. 1993. Resolution of cutaneous leishmaniasis: interleukin 12 initiates a protective $\mathrm{T}$ helper type 1 immune response. J. Exp. Med. 177:1797-1802.

29. Heinzel, F. P., D. S. Schoenhaut, M. Rerko, L. E. Rosser, and M. K. Gately. 1993. Recombinant interleukin 12 cures mice infected with Leishmania major. J. Exp. Med. 177:1505-1509.

30. Clerici, M., D. R. Lucey, J. A. Berzovsky, L. A. Pinto, T. A. Wynn, S. P. Blatt, M. J. Dolan, C. W. Hendrix, S. F. Wolf, and G. M. Shearer. 1993 Restoration of HIV-specific cell-mediated immune responses by interleukin-12 in vitro. Science (Wash. DC). 262:1721-1724.

31. Chan, S. H., B. Perussia, J. W. Gupta, M. Kobayashi, M. Pospisil, H. A. Young, S. F. Wolf, D. Young, S. C. Clark, and G. Trinchieri. 1991. Induction of interferon $\gamma$ production by natural killer cell stimulatory factor: characterization of the responder cells and synergy with other inducers. J. Exp. Med. 173:869879

32. Tripp, C. S., S. F. Wolf, and E. R. Unanue. 1993. Interleukin 12 and tumor necrosis factor are costimulators of interferon production by natural killer cells in severe combined immunodeficiency mice with listeriosis, and interleukin 10 is a physiologic antagonist. Proc. Natl. Acad. Sci. USA. 90:3725-3729.

33. Gazzinelli, R. T., S. Hieny, T. A. Wynn, S. Wolf, and A. Sher. 1993. Interleukin- 12 is required for the T-lymphocyte-independent induction of interferon- $\gamma$ by an intracellular parasite and induces resistance in T-cell-deficient hosts. Proc. Natl. Acad. Sci. USA. 90:6115-6119.

34. Daley, C. L., P. M. Small, G. F. Schecter, G. K. Schoolnik, R. A. McAdam, W. R. Jacobs, Jr., and P. C. Hopewell. 1992. An outbreak of tuberculosis with accelerated progression among persons infected with the human immunodeficiency virus. An analysis using restriction-fragment-length-polymorphisms. $N$. Engl. J. Med. 326:231-235.

35. DiPerri, G., M. Cruciani, M. C. Danzi, R. Luzzati, G. DeChecchi, M Malena, S. Pizzighella, R. Mazzi, M. Solbiati, and E. Concia. 1989. Nosocomia epidemic of active tuberculosis among HIV-infected patients. Lancet. ii:15021504.

36. Selwyn, P. A., D. Hartel, V. A. Lewis, E. E. Schoenbaum, S. H. Vermund, R. S. Klein, A. T. Walker, and G. H. Friedland. 1989. A prospective study of the risk of tuberculosis among intravenous drug users with human immunodeficiency virus infection. N. Engl. J. Med. 320:545-550.

37. Bermudez, L. E., and J. Champsi. 1993. Infection with Mycobacterium avium induces production of interleukin-10 (IL-10), and administration of antiIL-10 antibody is associated with enhanced resistance to infection in mice. Infect. Immun. 61:3093-3097.

38. Denis, M., and E. Ghadirian. 1993. IL-10 neutralization augments mouse resistance to systemic Mycobacterium avium infections. J. Immunol. 151:54255430.

39. Maggi, E., P. Parronchi, R. Manetti, C. Simonelli, M-P. Piccinni, F. Santoni, M. De Carli, M. Ricci, and S. Romagnani. 1992. Reciprocal regulatory effects of IFN- $\gamma$ and IL-4 on the in vitro development of human Th1 and Th2 clones. J. Immunol. 148:2142-2147.

40. Pearlman, E., J. W. Kazura, F. E. Hazlett, Jr., and W. H. Boom. 1993 Modulation of murine cytokine responses to mycobacterial antigens by helminth induced T helper 2 cell responses. J. Immunol. 151:4857-4864.

41. Toossi, Z., T. Young, P. Gogate, and J. J. Ellner. 1991. Expression of transforming growth factor- $\beta$ (TGF $\beta$ ) in lung granulomas and peripheral blood monocytes of patients with tuberculosis. Twenty-sixth Joint Conference on Tuberculosis and Leprosy. Seattle, WA. 57-62. (Abstr.)

42. Kobayashi, M., L. Fitz, M. Ryan, R. M. Hewick, S. C. Clark, S. Chan R. Loudon, F. Sherman, B. Perussia, and G. Trinchieri. 1989. Identification and purification of natural killer cell stimulatory factor (NKSF), cytokine with multiple biologic effects on human lymphocytes. J. Exp. Med. 170:827-845.

43. Bertagnolli, M. M., B-Y. Lin, D. Young, and S. H. Herrmann. 1992. IL-12 augments antigen-dependent proliferation of activated T lymphocytes. $J$. Immunol. 149:3778-3783.

44. Robertson, M. J., R. J. Soiffer, S. F. Wolf, T. J. Manley, C. Donahue, D. Young, S. H. Herrmann, and J. Ritz. 1992. Response of human natural killer cells to NK cell stimulatory factor (NKSF): cytolytic activity and proliferation of NK cells are differentially regulated by NKSF. J. Exp. Med. 175:779-788.

45. Gately, M. K., A. G. Wolitzky, P. M. Quinn, and R. Chizzonite. 1992 Regulation of human cytolytic lymphocyte responses by interleukin-12. Cell. Immunol. 143:127-142. 